
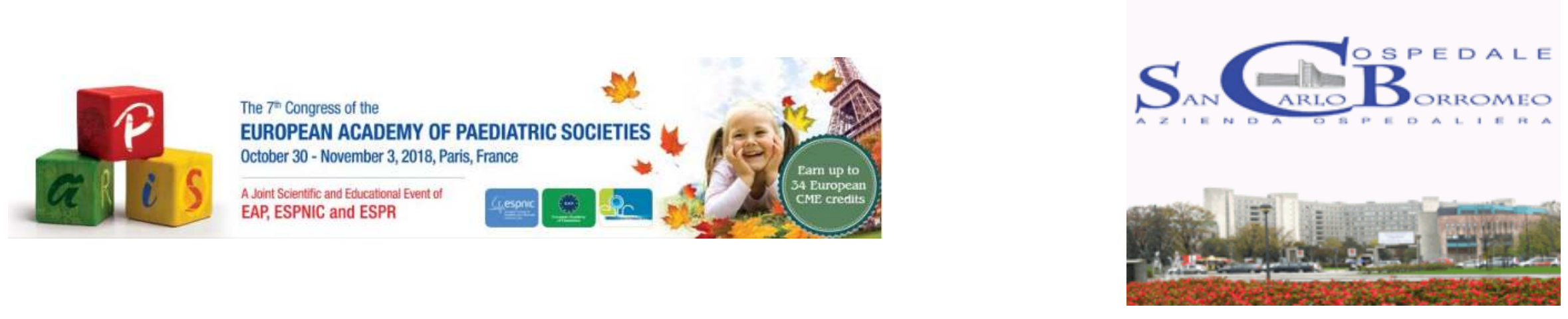

\title{
PEDIATRIC ACUTE ONSET NEUROPSYCHIATRIC SYNDROME (PANS) ASSOCIATED WITH MYCOPLASMA PNEUMONIAE INFECTION
}

Concetta Scalfaro, Alberto Podestà

Woman and Child Health department, San Carlo Borromeo Hospital-Milan (Italy)

\section{SUMMARY}

The acute-onset neuropsychiatric syndrome (PANS) is diagnosed on the basis of an abrupt beginning of obsessivecompulsive disorder (DOC) or the presence of at least two of a range of other neuropsychiatric symptoms (anxiety, depression, school impairment, somatic signs and symptoms such as sleep disorders, sensory/motor abnormalities). In addition to Streptococcus A, other pathogens have been recognized to contribute to the onset of acute neuropsychiatric disorders in young people including Mycoplasma Pneumoniae.

Mycoplasma Pneumoniae has been associated with a number of post infectious neurological disorders related to PANDAS LIKE infection and is strongly suspected of being a trigger for the PANS.

\section{CASE REPORT}

A.M., 10 years old male.

He arrived at the Emergency Room for abdominal pain, with normal neurological behavior. Initial physical examination revealed an afebrile boy who was awake and alert. Respiratory, abdominal and musculoskeletal examinations were normal.

During the medical examination the child presented acutely motor tics, choreiform movements of all limbs, behavior and mood disorders. The parents reported three months before intermittent low fever, dry cough and sore throat.

The patient's white blood cell count was $6.4 \times 10^{9} / \mathrm{L}$, lymphocyte count was $2.8 \times 10^{9} / \mathrm{L}$, platelet count was $209 \times 10^{9} / \mathrm{L}, \mathrm{C}$-reactive protein was $1.0 \mathrm{mg} / \mathrm{L}$. Toxicology screen and metabolic work-up were negative. The CT scan was normal. Cerebrospinal fluid analysis revealed a white blood cell count of $1.0 \times 10^{6} / \mathrm{L}$. Antistreptolysin O titre 180 U/L (normal <200 U/L), IgM mycoplasma pneumoniae titre $68 \mathrm{U} / \mathrm{ml}$ (normal $<10 / \mathrm{ml}$ ).
It was initiated therapy with clarithromycin $500 \mathrm{mg} /$ day. In the following five days the patient's agitation decreased significantly. Three weeks after the start of the treatment the patient was completely asymptomatic. Five weeks after the onset of acute symptoms clarithromycin was reduced to 250 mg/day. Antibiotic treatment was suspended after eight weeks.

\section{DISCUSSION}

The diversity of clinical presentation of young people with PANS always requires a careful and proper medical management. In front of a patient that manifests a sudden onset of psychiatric and physical symptoms, pediatricians should always consider the PANS in the differential diagnosis, collaborating if necessary with experts in other disciplines to diagnose and treat infection or inflammatory underlying disease.

\section{REFERENCES}

1. Frankovich J, Thienemann M, Rana S, Chang K. Five youth with pediatric acute-onset neuropsychiatric syndrome of differing etiologies.

Child Adolesc Psychopharmacol. 2015 Feb;25(1):31 7. doi: $10.1089 /$ cap.2014.0056

2. American Academy of Pediatrics. Mycoplasma pneumoniae and other Mycoplasma species infections. In: Red Book: 2018 Report of the Committee on Infectious Diseases, 31 st ed, Kimberlin DW, Brady MT, Jackson MA, Long SS (Eds), American Academy of Pediatrics, Itasca, IL 2018.

3. Swedo SE, Leckman JF, Rose NR. From Research Subgroup to Clinical Syndrome: Modifying the PANDAS Criteria to Describe PANS (Pediatric Acute-onset Neuropsychiatric Syndrome). Pediatr Therapeut 2012; 2:113. doi: 10.4172/21610665.1000113.

4. Ercan TE, Ercan G, Severge B, Arpaozu M, Karasu G. Mycoplasma pneumoniae infection and obsessivecompulsive disease: a case report. J Child Neurol. 2008 Mar;23(3):338-40. Epub 2007 Dec 13. 